\title{
Predictive Factors for Local Control and Survival in Patients with Cancer of Unknown Primary (CUP) Irradiated for Cerebral Metastases
}

\author{
DIRK RADES ${ }^{1,2}$, LIESA DZIGGEL ${ }^{1}$, STEFAN JANSSEN $^{1,3}$, MAI TRONG KHOA $^{2,4}$, VUONG NGOC DUONG $^{4}$, \\ VU HUU KHIEM ${ }^{4}$, NIKLAS GEBAUER ${ }^{5}$, TOBIAS BARTSCHT ${ }^{5}$ and STEVEN E. SCHILD ${ }^{6}$ \\ Departments of ${ }^{1}$ Radiation Oncology and of ${ }^{5}$ Hematology and Medical Oncology, \\ University of Lübeck, Lübeck, Germany; \\ ${ }^{2}$ Faculty of Medicine, Hanoi Medical University, Hanoi, Vietnam; \\ ${ }^{3}$ Private Practice of Radiation Oncology, Hannover, Germany; \\ ${ }^{4}$ Nuclear Medicine and Oncology Center, Bach Mai Hospital, Hanoi, Vietnam; \\ ${ }^{6}$ Department of Radiation Oncology, Mayo Clinic, Scottsdale, AZ, U.S.A.
}

\begin{abstract}
Background/Aim: To identify predictors of local control and survival after whole-brain irradiation (WBI) for cerebral metastases from cancer of unknown primary (CUP). Patients and Methods: In 140 patients receiving WBI alone or following resection, seven factors were investigated including treatment approach, WBI-regimen, age, gender, Eastern Cooperative Oncology Group (ECOG) performance score, number of cerebral lesions and extra-cerebral metastases. Results: On univariate analysis, resection plus WBI and boost $(p=0.002)$, ECOG $0-1 \quad(p<0.001)$ and a single lesion $(p<0.001)$ were positively associated with local control. On Cox regression, ECOG-score remained significant ( $p=0.002)$. On univariate analysis of survival, surgery plus WBI and boost $(p=0.009)$, ECOG $0-1 \quad(p<0.001)$, a single lesion $(p=0.024)$ and no extra-cerebral metastases $(p<0.001)$ were associated with better outcomes. On Cox regression, ECOGscore $(p<0.001)$ and extra-cerebral lesions $(p<0.001)$ were significant. Conclusion: Significant predictors of local control and survival were identified that contribute to treatment personalization and design of prospective trials in patients with cerebral metastases from CUP.
\end{abstract}

Despite modern diagnostic procedures, the origin of the primary tumor remains unknown in a considerable number of

Correspondence to: Prof. Dirk Rades, MD, Department of Radiation Oncology, University of Lübeck, Lübeck, Ratzeburger Allee 160, 23562 Lübeck, Germany. Tel: +49 45150045401, Fax: +49 45150045404, e-mail: rades.dirk@gmx.net

Key Words: Cancer of unknown primary (CUP), cerebral metastasis, whole-brain irradiation, local control, survival, prognoses. cancer patients (1). Many patients with cancer of unknown primary (CUP) have a disseminated stage of disease at the time of first diagnosis (2). Patients with CUP account for about $5 \%$ of those in whom cerebral metastases are detected $(1,3-5)$. Their prognosis is relatively poor when compared to patients with cerebral metastasis from other tumor entities like breast cancer and needs to be improved (3-6). In addition to new technologies and novel drugs, individualizing radiotherapy approaches may improve patient care. In order to avoid over- or undertreatment of a specific palliative situation, several factors should be considered when choosing for the best possible treatment program (3). Such factors include the patient's expected survival time and the possible results of the treatment, i.e. one should be aware of what can really be achieved $(4,5)$. Therefore, it would be adventageous for physicians to be able to use predictive factors to estimate both the expected outcome of the planned treatment and the patient's remaining lifespan. This study aimed to identify predictive factors for local (i.e. intracerebral) control of the disease and survival in a cohort of patients with cerebral metastases from CUP, who received whole-brain-irradiation (WBI) alone or following neurosurgical resection.

\section{Patients and Methods}

In the present study, data of 140 patients with brain metastases from CUP were evaluated. They were treated with WBI alone $(\mathrm{N}=113)$ or WBI following neurosurgical resection $(\mathrm{N}=27)$. Five of the patients received upfront surgery and a radiotherapy boost delivered to the bed of each resected lesion with WBI. WBI-regimens included $5 \times 4$ Gy in one week $(\mathrm{N}=38), 10 \times 3$ Gy in two weeks $(\mathrm{N}=70)$ and $15 \times 3$ Gy in three weeks $(\mathrm{N}=6)$ and $20 \times 2$ Gy in four weeks $(\mathrm{N}=26)$. The boost dose was either $5 \times 3$ Gy (following $10 \times 3$ Gy) or $5 \times 2$ Gy (following $20 \times 2$ Gy). 
Seven potential predictive factors were investigated regarding their impact on local control (defined as freedom from new cerebral metastases and recurrence/progression of the treated lesions) and survival following WBI. These factors included the treatment approach (WBI alone vs. upfront neurosurgery plus WBI vs. upfront neurosurgery plus WBI plus boost to the sites of resection), WBIregimen $(5 \times 4$ Gy vs. $10 \times 3$ Gy vs. $15 \times 3 \mathrm{~Gy} / 20 \times 2 \mathrm{~Gy})$, age at start of WBI ( $\leq 61$ years $v s . ~ \geq 62$ years, median=62 years), gender, Eastern Cooperative Oncology Group (ECOG) performance score (0-1 vs. 2 $v s .3-4)$, number of cerebral lesions (1 vs. 2-3 vs. $\geq 4)$ and extracerebral metastatic lesions (no vs. yes) (Table I). For univariate analysis of both local control and survival, we used the Kaplan-Meier method (7). The Kaplan-Meier curves of each factor were compared with the Wilcoxon test. Those factors found significant $(p<0.05)$ or showed a strong trend $(p<0.06)$ on univariate analysis were additionally included in a multivariable Cox regression analysis.

\section{Results}

On univariable analysis, neurosurgical resection followed by WBI plus boost $(p=0.002)$, ECOG score of $0-1 \quad(p<0.001)$ and presence of only one cerebral lesion $(p<0.001)$ had a significantly positive impact on local control (Table II). In addition, absence of extra-cerebral metastatic lesions $(p=0.053)$ showed a strong trend. On Cox regression analysis, the ECOG score remained significant (risk ratio $(\mathrm{RR})=1.69, \quad 95 \%$-confidence interval $\quad(\mathrm{CI})=1.21-2.37$, $p=0.002)$, whereas the treatment approach $(\mathrm{RR}=1.06$, $95 \% \mathrm{CI}=0.90-1.27, p=0.48$ ), the number of cerebral lesions $(\mathrm{RR}=1.06,95 \% \mathrm{CI}=0.86-1.32, p=0.59)$ and extra-cerebral lesions $(\mathrm{RR}=1.32,95 \% \mathrm{CI}=0.85-2.07, p=0.21)$ were no longer significantly associated with local control.

On univariate analysis of survival, surgery followed by WBI plus boost $(p=0.009)$, ECOG score of $0-1 \quad(p<0.001)$, only one cerebral lesion $(p=0.024)$, and absence of extracerebral metastatic lesions $(p<0.001)$ were significantly associated with a better outcome (Table III). On Cox regression analysis, the ECOG score $(\mathrm{RR}=2.22,95 \% \mathrm{CI}=1.63$ $3.03, p<0.001)$ and extra-cerebral lesions $(\mathrm{RR}=2.31$, $95 \% \mathrm{CI}=1.55-3.49, p<0.001)$ maintained their significant association with survival, whereas treatment approach $(\mathrm{RR}=1.01,95 \% \mathrm{CI}=0.88-1.17, p=0.85)$ and number of cerebral lesions $(\mathrm{RR}=1.16,95 \% \mathrm{CI}=0.97-1.38, p=0.10)$ did not.

\section{Discussion}

A considerable number of studies have been performed in patients with CUP of the head and neck region including identification of prognostic factors (8-10). Far fewer studies are available that focused on patients irradiated for metastases from CUP including vertebral lesions and cerebral lesions (11-13). Many patients with cerebral metastases from CUP have a poor prognosis that must be improved (12). In order to achieve this goal, a clear understanding of significant predictive factors associated
Table I. Summary of potential predictive factors included in this study.

\begin{tabular}{lc}
\hline & Number of patients $(\%)$ \\
\hline Treatment approach & $113(81)$ \\
WBI alone & $22(16)$ \\
Surgery + WBI & $5(4)$ \\
Surgery + WBI + boost & \\
WBI-regimen & $38(27)$ \\
$5 \times 4$ Gy & $70(50)$ \\
$10 \times 3$ Gy & $32(23)$ \\
$15 \times 3$ Gy/20×2 Gy & \\
Age & $67(48)$ \\
$\leq 61$ years & $73(52)$ \\
$\geq 62$ years & \\
Gender & $46(33)$ \\
Female & $94(67)$ \\
Male & \\
ECOG performance score & $44(31)$ \\
$0-1$ & $56(40)$ \\
2 & $40(29)$ \\
$3-4$ & $40(29)$ \\
Number of cerebral lesions & $18(13)$ \\
1 & $82(59)$ \\
$2-3$ & $66(47)$ \\
$\geq 4$ & $74(53)$ \\
Extra-cerebral metastases & \\
No &
\end{tabular}

WBI: Whole-brain-irradiation; ECOG: Eastern Cooperative Oncology Group.

with treatment outcomes in terms of local (intracerebral) control and survival would be helpful. The current study aimed to contribute to the identification of such factors in a series of 140 patients who received WBI alone or following resection of metastatic lesions with or without a radiation boost to the beds of the resected metastases.

The treatment approach was significantly associated with local control, on univariable analysis. Surgery followed by WBI and a boost to the metastatic sites achieved the best local control rates, followed by surgery plus WBI and WBI alone. The finding that resection plus WBI and a boost was superior to resection plus WBI without an additional boost has been previously shown for patients with a single brain metastasis or those with a limited number of lesions from various primaries $(14,15)$. In a retrospective study of 195 patients with different primary tumors and a single brain metastasis, the 2-year local control rates were $51 \%$ after surgery plus WBI plus boost compared to $20 \%$ after surgery plus WBI ( $p=0.002)(14)$. In another study of 201 patients with a limited number of cerebral lesions from various tumor entities, the treatment approach was an independent predictor of local control ( $\mathrm{RR}=2.15, p=0.002)$ in favor of the addition of a boost to surgery followed by WBI (15). Also, in the 
Table II. Local control rates at 6 and 12 months following WBI.

\begin{tabular}{|c|c|c|c|}
\hline & $\begin{array}{c}\text { At } 6 \text { months } \\
(\%)\end{array}$ & $\begin{array}{c}\text { At } 12 \text { months } \\
(\%)\end{array}$ & $p$-Value \\
\hline \multicolumn{4}{|l|}{ Treatment approach } \\
\hline WBI alone & 29 & 19 & \\
\hline Surgery + WBI & 59 & 32 & \\
\hline Surgery + WBI + boost & 80 & 80 & 0.002 \\
\hline \multicolumn{4}{|l|}{ WBI-regimen } \\
\hline $5 \times 4$ Gy & 41 & 27 & \\
\hline $10 \times 3 \mathrm{~Gy}$ & 30 & 19 & \\
\hline $15 \times 3 \mathrm{~Gy} / 20 \times 2 \mathrm{~Gy}$ & 42 & 31 & 0.43 \\
\hline \multicolumn{4}{|l|}{ Age } \\
\hline$\leq 61$ years & 37 & 27 & \\
\hline$\geq 62$ years & 34 & 20 & 0.18 \\
\hline \multicolumn{4}{|l|}{ Gender } \\
\hline Female & 36 & 19 & \\
\hline Male & 35 & 28 & 0.78 \\
\hline \multicolumn{4}{|l|}{ ECOG performance score } \\
\hline $0-1$ & 51 & 36 & \\
\hline 2 & 38 & 25 & \\
\hline $3-4$ & 13 & 0 & $<0.001$ \\
\hline \multicolumn{4}{|l|}{ Number of cerebral lesions } \\
\hline 1 & 61 & 47 & \\
\hline $2-3$ & 28 & n.a. & \\
\hline$\geq 4$ & 25 & 14 & $<0.001$ \\
\hline \multicolumn{4}{|l|}{ Extra-cerebral metastases } \\
\hline No & 43 & 32 & \\
\hline Yes & 27 & 11 & 0.053 \\
\hline Whole series & 36 & 24 & \\
\hline
\end{tabular}

WBI: Whole-brain irradiation; ECOG: Eastern Cooperative Oncology Group; n.a.: not available; bold $p$-Values=significant.

univariate analysis of the present study, the ECOG score and the number of cerebral lesions were associated with local control. The ECOG score was significant on both univariable and multivariable analyses. These findings are consistent with those from a large previous study of 1,797 patients irradiated for brain metastases from various types of primary tumors (4). In that study, both performance status and number of cerebral lesions were independent predictors of local control.

In the current study, the treatment approach, the ECOG score, the number of cerebral lesions and extra-cerebral metastatic lesions were associated with survival on univariable analysis. In addition, the ECOG score and extracerebral metastatic lesions achieved significance also on multivariable analysis. Again, these findings are consistent with the results of other studies performed in patients with cerebral metastases from different primaries $(14,15)$. In the study of 195 patients with a single brain metastasis, a trend was found (14). The 2-year survival rates were $40 \%$ after surgery plus WBI plus boost compared to $25 \%$ after surgery plus WBI $(p=0.11)$. In the study of 201 patients with a limited number of cerebral lesions, surgery plus WBI plus
Table III. Survival rates at 6 and 12 months following WBI.

\begin{tabular}{|c|c|c|c|}
\hline & $\begin{array}{c}\text { At } 6 \text { months } \\
(\%)\end{array}$ & $\begin{array}{c}\text { At } 12 \text { months } \\
(\%)\end{array}$ & $p$-Value \\
\hline \multicolumn{4}{|l|}{ Treatment approach } \\
\hline WBI alone & 27 & 15 & \\
\hline Surgery + WBI & 50 & 21 & \\
\hline Surgery + WBI + boost & 80 & 60 & 0.009 \\
\hline \multicolumn{4}{|l|}{ WBI-regimen } \\
\hline $5 \times 4$ Gy & 29 & 14 & \\
\hline $10 \times 3 \mathrm{~Gy}$ & 27 & 17 & \\
\hline $15 \times 3 \mathrm{~Gy} / 20 \times 2 \mathrm{~Gy}$ & 50 & 22 & 0.25 \\
\hline \multicolumn{4}{|l|}{ Age } \\
\hline$\leq 61$ years & 37 & 20 & \\
\hline$\geq 62$ years & 29 & 15 & 0.77 \\
\hline \multicolumn{4}{|l|}{ Gender } \\
\hline Female & 37 & 16 & \\
\hline Male & 31 & 19 & 0.87 \\
\hline \multicolumn{4}{|l|}{ ECOG performance score } \\
\hline $0-1$ & 61 & 33 & \\
\hline 2 & 29 & 19 & \\
\hline $3-4$ & 8 & 0 & $<0.001$ \\
\hline \multicolumn{4}{|l|}{ Number of cerebral lesions } \\
\hline 1 & 45 & 28 & \\
\hline $2-3$ & 33 & 0 & \\
\hline$\geq 4$ & 27 & 13 & 0.024 \\
\hline \multicolumn{4}{|l|}{ Extra-cerebral metastases } \\
\hline No & 47 & 34 & \\
\hline Yes & 20 & 2 & $<0.001$ \\
\hline Whole series & 33 & 18 & \\
\hline
\end{tabular}

WBI: Whole-brain irradiation; ECOG: Eastern Cooperative Oncology Group; bold $p$-Values=significant.

boost resulted in a significantly better survival than surgery plus WBI on both univariate (1-years survival rates $66 \%$ vs. $41 \%, p<0.001)$ and multivariate analysis $(\mathrm{RR}=1.94$, $p=0.010$ ) (15). In the large study of 1,797 patients, better performance status score, lower number of cerebral lesions and absence of extra-cerebral metastases were independently associated with an improved survival (4).

The predictive factors identified in this study can be used for defining the best suitable treatment for an individual with cerebral metastases from CUP. In general, patients with poor expected outcomes should receive a less burdensome treatment with a major focus on prevention or control of symptoms and preservation or improvement of the patient's quality of life. Patients with one or two lesions may benefit from upfront surgery in addition to WBI in terms of better local control and survival. However, one should be aware of the findings from a matched-pair study that only the complete removal of all metastatic lesions leads to a better survival prognosis (16). Many patients with few cerebral lesions are good candidates for stereotactic radiosurgery, either alone or in combination with WBI $(3,13,17,18)$. 
In summary, this study identified significant predictors of local control and survival in patients irradiated for cerebral metastases from CUP. These predictors contribute to personalization of the treatment and to proper design of future clinical trials.

\section{Conflicts of Interest}

On behalf of all Authors, the corresponding Author states that there is no conflict of interest related to this study.

\section{References}

1 Siegel RL, Miller KD and Jemal A: Cancer statistics, 2017. CA Cancer J Clin 67: 7-30, 2017.

2 Rades D, Kühnel G, Wildfang I, Börner AR, Schmoll HJ and Knapp W: Localised disease in cancer of unknown primary (CUP): the value of positron emission tomography (PET) for individual therapeutic management. Ann Oncol 12: 1605-1609, 2001.

3 Tsao MN, Rades D, Wirth A, Lo SS, Danielson BL, Gaspar LE, Sperduto PW, Vogelbaum MA, Radawski JD, Wang JZ, Gillin MT, Mohideen N, Hahn CA and Chang EL: Radiotherapeutic and surgical management for newly diagnosed brain metastasis(es): An American Society for Radiation Oncology evidence-based guideline. Pract Radiat Oncol 2: 210-25, 2012.

4 Rades D, Dziggel L, Haatanen T, Veninga T, Lohynska R, Dunst $\mathrm{J}$ and Schild SE: Scoring systems to estimate intracerebral control and survival rates of patients irradiated for brain metastases. Int J Radiat Oncol Biol Phys 80: 1122-1127, 2011.

5 Dziggel L, Segedin B, Podvrsnik NH, Oblak I, Schild SE and Rades D: Validation of a survival score for patients treated with whole-brain radiotherapy for brain metastases. Strahlenther Onkol 189: 364-366, 2013.

6 Rades D, Lohynska R, Veninga T, Stalpers LJ and Schild SE: Evaluation of 2 whole-brain radiotherapy schedules and prognostic factors for brain metastases in breast cancer patients. Cancer 110: 2587-2592, 2007.

7 Kaplan EL and Meier P: Non-parametric estimation from incomplete observations. J Am Stat Assoc 53: 457-481, 1958.

8 Sivars L, Landin D, Grün N, Vlastos A, Marklund L, Nordemar S, Ramqvist T, Munck-Wikland E, Näsman A and Dalianis T: Validation of human papillomavirus as a favourable prognostic marker and analysis of CD8+ tumour-infiltrating lymphocytes and other biomarkers in cancer of unknown primary in the head and neck region. Anticancer Res 37: 665-673, 2017.
9 Friedrich RE and Zustin J: Mucoepidermoid carcinoma unknown primary affecting the neck. Anticancer Res 36: 31693171, 2016.

10 Sivars L, Tani E, Näsman A, Ramqvist T, Munck-Wikland E and Dalianis T: Human papillomavirus as a diagnostic and prognostic tool in cancer of unknown primary in the head and neck region. Anticancer Res 36: 487-493, 2016.

11 Douglas S, Huttenlocher S, Bajrovic A, Rudat V, Schild SE and Rades D: Prognostic factors for different outcomes in patients with metastatic spinal cord compression from cancer of unknown primary. BMC Cancer 12: 261, 2012.

12 Rades D, Bohlen G, Lohynska R, Veninga T, Stalpers LJ, Schild SE and Dunst J: Whole-brain radiotherapy with 20 Gy in 5 fractions for brain metastases in patients with cancer of unknown primary (CUP). Strahlenther Onkol 183: 631-636, 2007.

13 Dziggel L, Bajrovic A, Schild SE and Rades D: Stereotactic radiosurgery alone for one to two brain metastases from cancer of unknown primary. Anticancer Res 38: 565-567, 2018.

14 Rades D, Kueter JD, Gliemroth J, Veninga T, Pluemer A and Schild SE: Resection plus whole-brain irradiation versus resection plus whole-brain irradiation plus boost for the treatment of single brain metastasis. Strahlenther Onkol 188: 143-147, 2012.

15 Rades D, Pluemer A, Veninga T, Dunst J and Schild SE: A boost in addition to whole-brain radiotherapy improves patient outcome after resection of 1 or 2 brain metastases in recursive partitioning analysis class 1 and 2 patients. Cancer 110: 15511559, 2007.

16 Bindal RK, Sawaya R, Leavens ME and Lee JJ: Surgical treatment of multiple brain metastases. J Neurosurg 79: 210-216, 1993.

17 Rades D, Huttenlocher S, Hornung D, Blanck O and Schild SE: Radiosurgery alone versus radiosurgery plus whole-brain irradiation for very few cerebral metastases from lung cancer. BMC Cancer 14: 931, 2014.

18 Huttenlocher S, Dziggel L, Hornung D, Blanck O, Schild SE and Rades D: A new prognostic instrument to predict the probability of developing new cerebral metastases after radiosurgery alone. Radiat Oncol 9: 215, 2014. 